\title{
An approach to craniomandibular dysfunction in dento-facial orthopedics
}

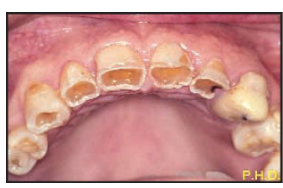

\author{
P.H. DUPAS, G. DUPAS, S. DESMONS, F. GRAUX
}

\begin{abstract}
Without realizing it, orthodontists may find themselves treating patients suffering from cranio-mandibular disorders, who may be adults, but not necessarily. Both young children and adolescents can also have these problems. Orthodontists often fall into the trap of not recognizing these disorders especially when the clinical signs are discreet or even non-existent. In order to save orthodontists from encountering unpleasant post-treatment surprises, we present in this paper a review of some of the indications of the etiology of craniomandibular dysfunction, how to diagnose it, and the importance of its major clinical signs that can be a great help to them in achieving a keener state of vigilance in this regard throughout orthodontic therapy.
\end{abstract}

\section{KEYWORDS}

\section{Bruxism}

Diagnosis of craniomandibular dysfunction

Posture

Oculogyria.

Address for correspondence:

Ph. DUPAS,

G. DUPAS,

S. DESMONS,

F. GRAUX,

Faculté de Chirurgie Dentaire

Université de Lille 2,

place de Verdun,

59000 Lille. 


\section{1 - INTRODUCTION}

General dentists often express a reluctance to refer patients to orthodontists for fear that mechano-therapy will put them at risk of developing painful symptoms during mastication in what was frequently referred to as TMJ and, later, TMD, TemperoMandibular Joint Disorder. But all the symptoms that were said to characterize this malfunction do not necessarily appear at the same time and can occur alone or in clusters so it cannot accurately be described as a syndrome. And, in addition, the same causes do not routinely produce the same effect. So while in some quarters the nomenclature TMD is still employed, we prefer to call it simply craniomandibular dysfunction ${ }^{6}$.

Because individuals function as complete units, we feel obliged to conceptualize the stomato-gnathic system in close relationship to the ensemble of the body. So in our view a diagnosis of craniomandibular dysfunction must, take causes and effects exterior to the oro-facial sphere more and more into account. Our most recent studies show that painful malfunction of the masticatory apparatus extend well beyond the oro-facial region to involve general posture as well as the eyes. Without actually becoming specialists in the field, today's well informed general dentist will include a review of the ocular system of patients they are examining for craniomandibular dysfunction $^{3,8}$.

Recently available data shows that craniomandibular dysfunction does not, as previously supposed, primarily affect women around 45 years old ${ }^{2,26}$ More delicate diagnostic procedures have shown that it also afflicts adolescents and young adults. Some $75 \%$ of the population suffers from articular problems, which appear to be occurring more and more frequently in today's world. In a specialized facility like that of the Centre Abel Caumartin of the C.H.R.U. in Lille, nearly $90 \%$ of the patients who sought treatment for craniomandibular dysfunction of the masticatory system were found to have forward positioning of the disc. This high percentage shows how important it is for dentists and orthodontists to be aware that this condition may be present in any of their patients, no matter what their ages, and to make a swift diagnosis. The difficulty in their achieving this derives from the frequent absence of any clear clinical signs that the disc is lies in a forward position especially when the pathological disturbance is of long standing. The failure to make a proper diagnosis of this condition in a young adult can result in the occurrence of disturbing problems after the completion of orthodontic treatment.

Orthodontic forces do not in themselves generate cranio mandibular disturbances, but the undertaking of orthodontic treatment in a patient where no signs of this problem were evident or were undetected can exacerbate it and cause its frank, and embarrassing, appearance after the conclusion of treatment. The same thing is true of problems related to posture and vision that do not occur exclusively in adults. 


\section{2 - THE ESTABLISHMENT OF CRANIO-MANDIBULAR MALFUNCTION}

Before practitioners can consider making a diagnosis of craniomandibular dysfunction of the masticatory system they must first its etiopathology. In both muscular and articular malfunction patients experience pain only in bruxism. Muscular spasms seem to be caused by imperfections of occlusion, but the causes of articular problems are even less well understood.

\section{2 - 1 - Occlusal contacts}

Under normal conditions the teeth of the two jaws come into contact only during deglutition, which occurs about 500 to 2000 times a day, either at the termination of mastication for 200 milliseconds or when the mouth is empty for salivation for 600 milliseconds. These daily dental contacts, then, are short lived and add up to only about 30 minutes per day. Various mandibular movements, whether or not undertaken voluntarily, are controlled by sub-cortical regions of the brain, bulbular or peripheral. At all other times the mandible drops slightly under its own weight and the forces of gravity, assuming a physiological rest position regulated by harmonious muscular contractions, in the absence of any dental jaw to jaw contact. This is a state of affairs that allows mandibular structures to economize their activities.

The reticular formation, in conjunction with the thalamus and the cortex, coordinates and regulates the activities of the clusters of cranial nerves. It

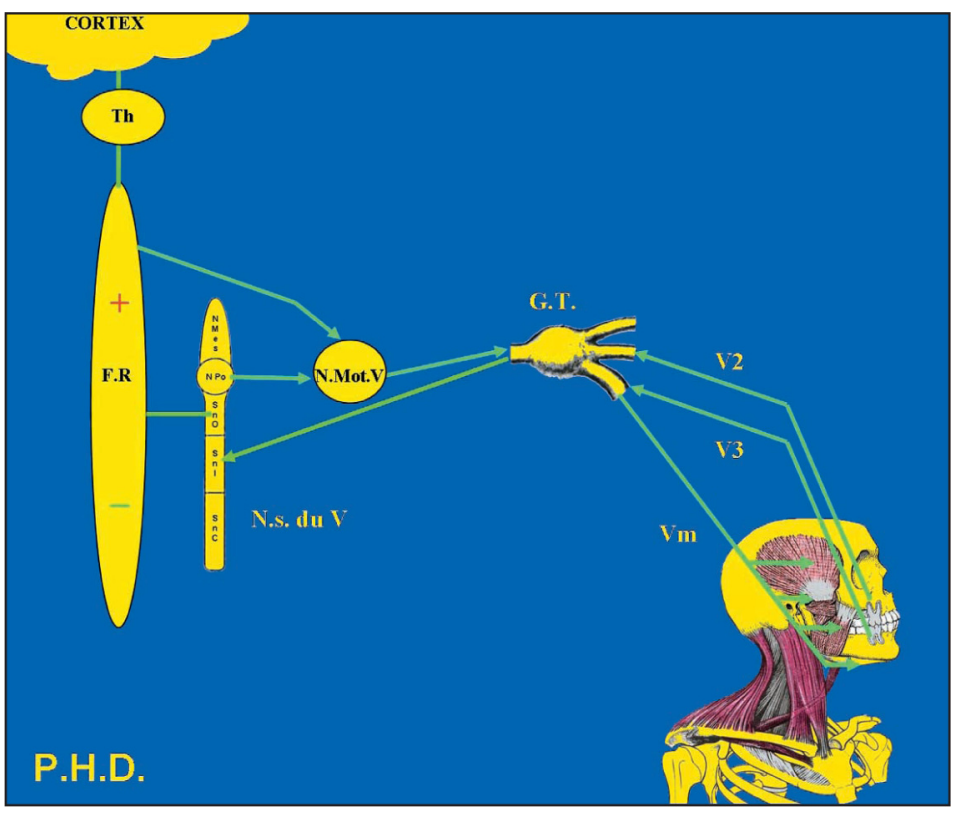

Figure 1

The regulating role played by the reticular formation in the contraction of the muscles of mastication.

Th: Thalamus; F.R.: Formation Réticulaire; N.s du V: Noyau sensitif du V; G.T.: Ganglion Trigéminal 
therefore controls, by its functioning as an excitor in its mesencephalic portion and as an inhibitor in its bulbar sector, the motor center of the fifth cranial nerve which directs the actions of the muscles of mastication. Their coordinated and harmonious contractions, accordingly, depend on the regulatory role played by the reticular formation $[5,6]$, which, as a result, also directs the functioning of the tempero-mandibular joint. The teeth then come into contact through the action of the elevator muscles that contract symmetrically, correctly positioning the condyles that are covered by their discs in their respective mandibular fossae (fig. 1).

\section{2 - 2 - Bruxism}

Repeated clenching and grinding of teeth are unconscious emotional

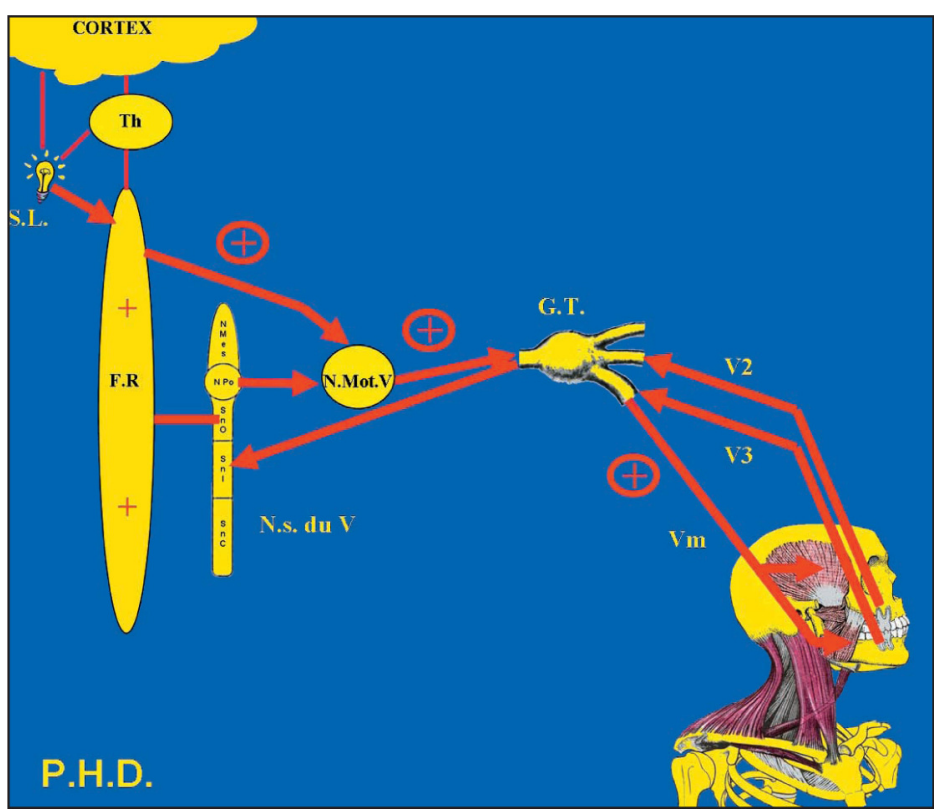

responses to stress and repression of problems that a person is unable or unwilling to express on a conscious level. This physical manifestation of a psychosomatic conflict through frequent harsh centric or eccentric contact of opposing teeth is called bruxism and is a dental reflection of an individual's psychic malaise. Bruxism comes under the control of the limbic system, the behavioral center of personality, which is made up of numerous structures including the hypothalamus and the amygdal. When their amygdal are stimulated rats and monkeys begin chewing motions and swallowing action. Stimulation of the hypothalamus of rabbits triggers reflex activation of the elevator muscles of the mandible ${ }^{12}$ (fig. 2).

When animals are in a state of discomfort or suffering from stress or other behavioral difficulties, the limbic system acts on the reticular formation
Figure 2

The influence of the limbic system on the reticular formation and on contraction of the muscles of mastication.

S.L.: Système Limbique; Th: Thalamus; F.R.: Formation Réticulaire; N.s du V: Noyau sensitif du V; G.T.: Ganglion Trigéminal 
to lessen its regulatory activities so that it performs essentially as an excitor. This reticular hyperactivity disorganizes control of the contraction of the elevator muscles causing them to remain in a state of permanent contraction. Bruxism ensues and is maintained by this deregulation so long as the psychological problems continue to be uncontrolled $20,24,27,33$. Dentists can perceive some or all of the signs of this syndrome in worn spots on the teeth, small fractures, and the patient's painful muscular spasms as well as by internal derangement of the temperomandibular joint.

\section{2 - 3 - Etiology of muscular problems}

In the presence of bruxism, the resultant intense and uncoordinated muscular activity exceeds the individual's physiological adaptive capability and the muscles of mastication are unable to recuperate. This hyperactivity provokes not only muscular hypertrophy but also an increase, an over-consumption of oxygen by the cells causing them to increase the release of carbon dioxide. This lack of balance results in the storage in the cells of the muscles of mastication of considerable amounts of carbon dioxide, which leads to the formation of lactic acid and accompanying painful muscular cramps. This concludes in creating a muscular type of craniomandibular dysfunction that is usually the patient's chief complain in consultation $^{1,29}$.

\section{2 - 4 - Etiology of tempero- mandibular joint problems}

A forward positioning of the disc is the most frequent manifestation of tempero-mandibular joint problems, a condition that can only result from some untoward event. In a healthy joint, the articular disc is held firmly on the head of the condyle by ligaments that are so strong that only harsh and extreme maneuvers can disturb the harmony of this arrangement. Damage to this ensemble can occur in the course of general anesthesia when the intubation must be accomplished speedily to avoid provoking spasms of the glottis. Despite the patient's relaxed condition, the anesthetist may find access to the upper airways difficult enough to require excessive mandibular movements that stretch the disc holding ligaments. No longer firmly held to the condyle, the disc may tilt forward and stay there in a forward position ${ }^{6}$. This condition can also appear after removal of third molars under general anesthesia when the patient's loss of conscious muscular control can permit the mandible to open beyond its usual physiological limit as the surgeon achieves better access to the extraction site. This causes the ensemble of disc/condyle to wander forward over the anterior maxillary tuberosity, stretching the ligaments. Once distended, a ligament never returns to its original length, losing its ability to function as designed. When the procedure is concluded, the condyle 


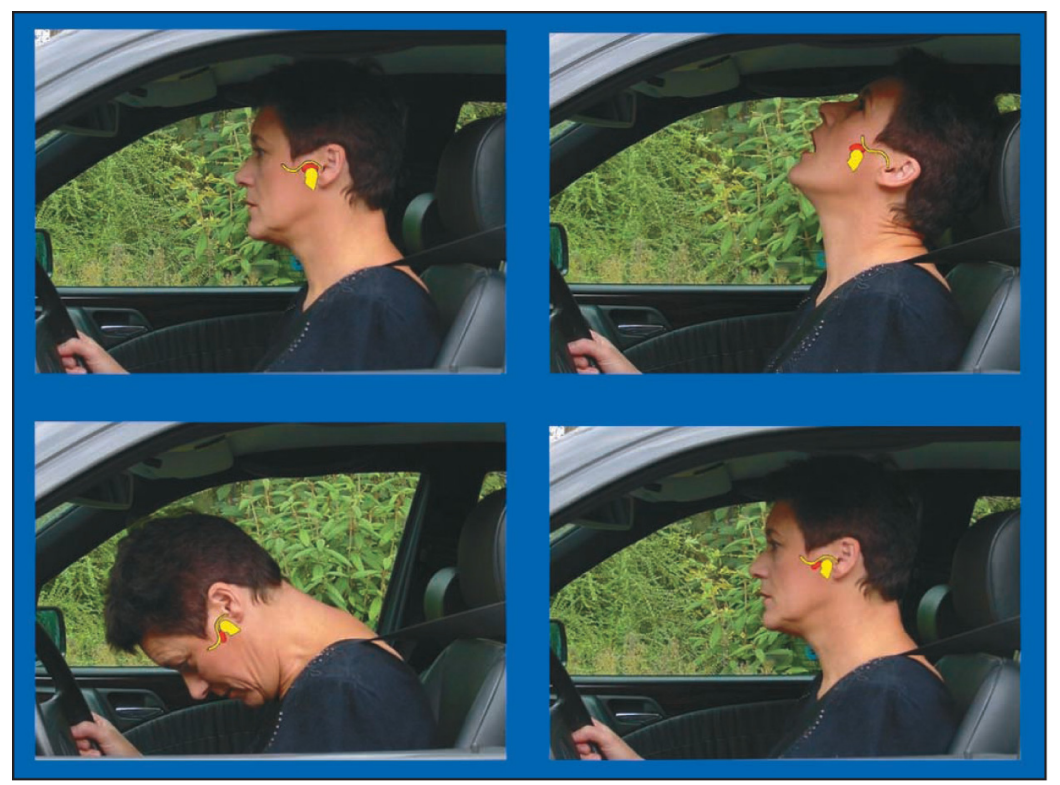

Figure 3

The rabbit punch.

returns to its fossa but the disc remains in a forward position. This is frequently seen in young adults who complain of noises and pain in the tempero-mandibular joint after the conclusion of orthodontic treatment.

During the intake interview, the examining practitioner often hears the same scenario from patients who, having just completed orthodontic treatment, have been advised to have four wisdom teeth removed to avoid relapse. Because of the tight constraints of a tight university academic schedule, many have decided to have these extractions performed under general anesthesia during vacation so as to interfere with their studies as little as possible. A forward positioning of the disc occurring at this time may at first be un-noticed but as the stress of school work begins to intensify the students may start suffering from TMD pain. Orthodontists are often accused of being responsible for this unwelcome outcome especially if they have employed extra-oral force in their treatment. The frequency of this scenario should not, however deter orthodontists from using this treatment arm prudently even in cases of organic or acquired flaccidity of tempero- mandibular ligaments.

Unfortunately, it is not just extended mandibular movements under general anesthesia that can provoke an anterior positioning of the disc; a "rabbit punch" or a whiplash injury can also be responsible particularly when the ligaments are insufficiently taut. Cases of motorist who have been rear-ended are significant ${ }^{41}$. When this happens the blow from behind propels the condylo-discal complex 
forward over the anterior temporal tuberosity. In the after shock the condyles usually return to their fossae but leave the discs behind. The stretching of the ligaments that results is immediate and irreversible (fig. 3). This permanent stretching makes the ligaments forever incapable of performing their role of keeping the disc in place, with the resultant functional disharmony of the temperomandibular joint characterized by an anterior tilt of the disc ${ }^{32}$.

Orthodontists must therefore make prudence their watchword before inaugurating any course of orthodontic treatment, every day more so as our society grows increasingly litigious. During their intake examinations of all patients, orthodontists must be alert to the slightest signs of craniomandibular disorder because these problems will not manifest themselves if patients do not clench or grind their teeth. Clinical symptoms of pain arising later that impel patients to consult so-called TMD experts may then become a source of conflict between the patient and the orthodontist. Then it will be too late to warn the orthodontists to be diligent in making a diagnosis of TMD mal function before beginning treatment.

\section{2 - 5 - The clinical picture of condylo-discal problems}

Condylo-discal disorders manifest themselves as a mal-arrangement of the relationship between the disc and its condyle. In jaw opening, the condyle passes over the posterior border of the disc to position itself under it. This is accompanied by articular sounds of varying intensity depending on the extent of wear on the posterior edge of the disc. The more intact it is, the louder the sound will be. As mouth opening proceeds, the mandible de-

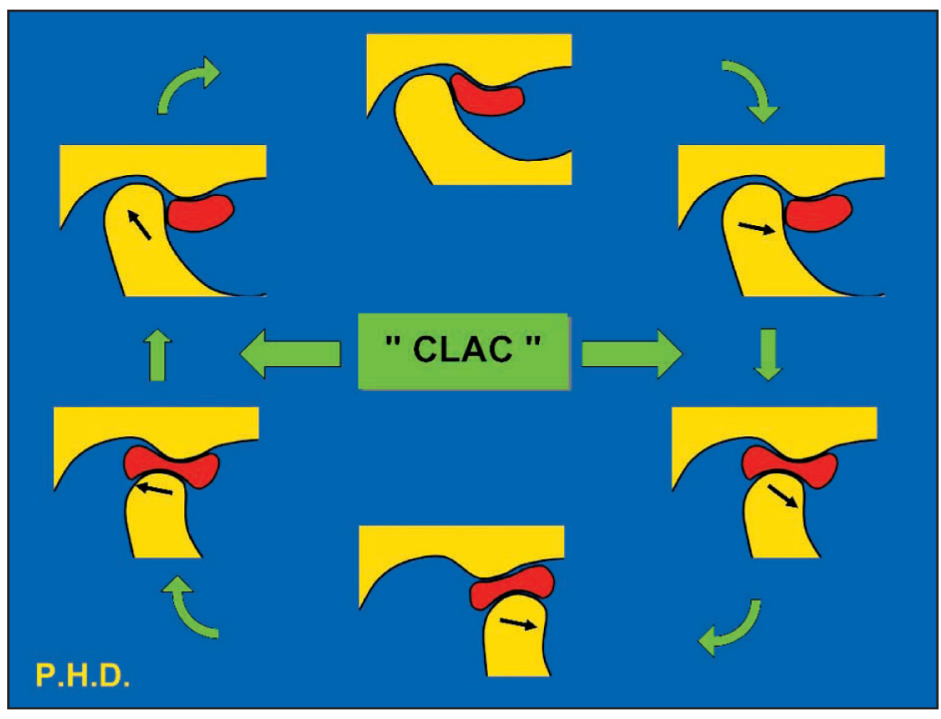

Figure 4

Schema of a reducible forward positioned disc. 
viates toward the pathologically affected side and then recenters itself when the condyle finds its disc. In closure this little minuet reverses itself. The anterior displacement of the disc reveals itself with a clicking on the round trip that is more or less premature depending on how far advanced the disc is from the condyle. It is therefore possible to distinguish a reducible anterior position of the disc in the beginning, the middle, or the termination of mouth opening ${ }^{9}$ (fig. 4).

A clicking sound in the articular space can also be heard in the beginning of propulsive mandibular movement in cases of reducible anterior disc displacement. In this situation, in view of the early recovery of the disc, makes a more favorable diagnosis possible. Because the anterior displacement can be recovered clinically its recapture can be anticipated.

On the other hand orthodontists would be well advised not to attempt to recapture the disc when its displacement occurs in the middle or at the end of mouth opening. In such cases the ligaments are too stretched to be able to hold the disc in place on the condyle. In such cases, where anterior disc displacement cannot be recovered clinically, relapse is likely to ensue after recapture.

Anterior displacement can be totally non reducible or irreversible (fig. 5). When the disc has tilted completely in advance of the condyle, it can never come back spontaneously because its ligaments that are continuously under stress become more and more stretched out. Depending upon their flexibility, the blockage of the articulation can show up in the patient's reduced ability for mouth opening or for the opposite, an extremely wide opening. This condition can develop slowly or appear suddenly after some type of trauma such as a "rabbit punch" or after general anesthesia.

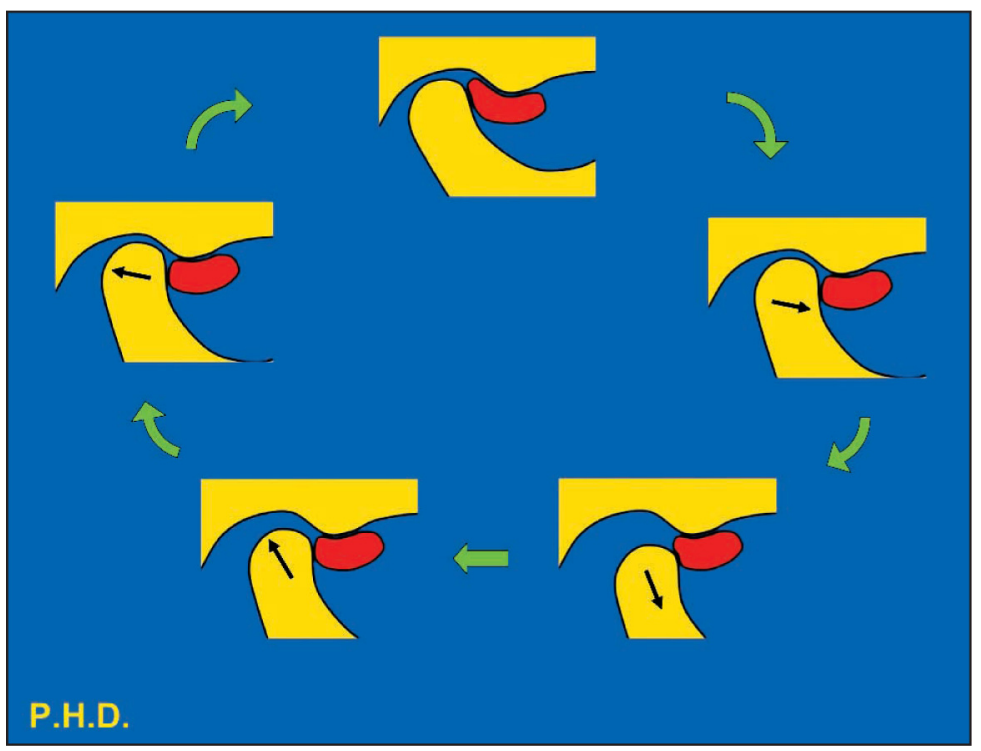

Figure 5

Schema of a forward positioned disc that cannot be repositioned. 
The cessation of articular clicking sounds is not an indication of healing. In fact quite the opposite is true because this lack of noise indicates that the disturbance in the articulation has passed from a stage of possible reversibility to one of irreversibility. All old states of entrenched pathosis pass through a stage of pseudo-normality that clouds diagnostic efforts. So orthodontists should carefully note with suspicion the condition of patients who can open so well that they can extend the vertical movement as far as 65 millimeters. Looseness of ligaments, physiological or pathological, can produce the same effects so the examiner should identify the cause by using the finger test. A finger that depresses the mandible and then comes back readily is a sign of patient's hyperrelaxation. Even if this ligamentary looseness is physiological, orthodontists should exercise extreme care with patients who demonstrate and elect to treat them only with light forces (fig. 6).
When anterior displacement cannot be corrected, the head of the condyle no longer benefits from the protection of the disc and rests on the upper ligament. It is then virtually in osseous contact with its maxillary antagonist and is subjected to adaptive changes of its cortical bone that lead to degenerative arthritis of the temperomandibular joint. The articular sounds that had disappeared return in the form of creaking noises or crepitation $^{6,29,38}$.

It is never certain that an anterior displacement of the disc will continue to worsen. A displacement that is reducible at the beginning of mouth opening may not become aggravated. Some may even become reducible in later stages and then, finally become irreducible. Others may be irreducible from the start and stay that way. Everything depends on the capabilities of the ligamentary system associated with the articular disc on its condyle.

When bruxism more severe than usual is noted at night, examiners

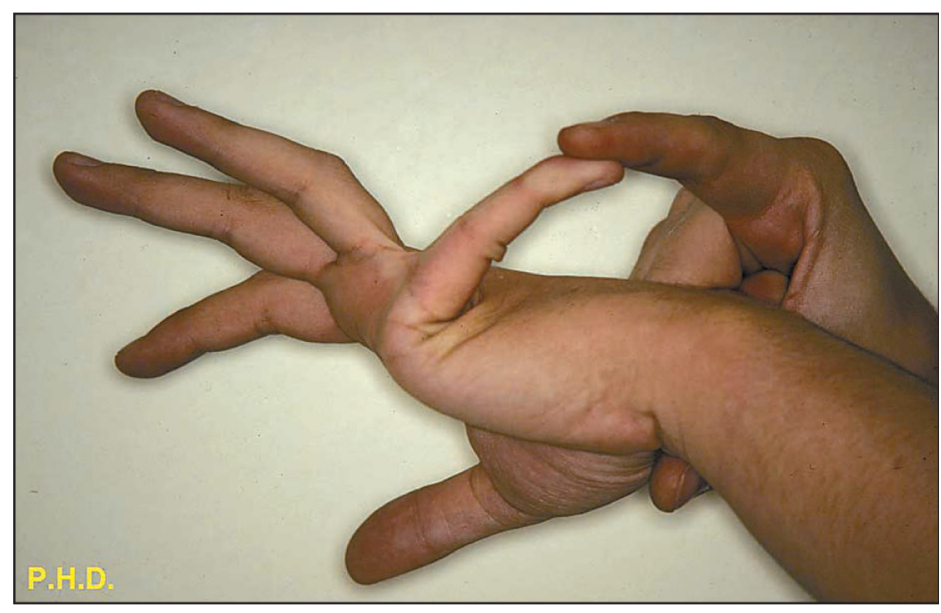

Figure 6

Finger palpation of the joint. 
usually observe that anterior displacement that had been reducible becomes, over time, irreducible. The patient who had had articular noise in relatively normal opening finds one day that mouth opening has become limited and unaccompanied by any articular sounds. This has resulted from a sudden nocturnal tilting of the disc, which is now located further forward on the condyle at, or near the point of irreversibility. Orthodon- tics should, in these cases, exercise therapeutic prudence. Extraoral force is contra-indicated. In cases of nonadaptation to craniomandibular dysfunction, individuals compensate as well as their individual capacities will allow, de-compensating when the pathological process becomes truly installed. This decompensation may be confined to the oro-facial sphere or extend enough to involve posture and the eye.

\section{3 - DIAGNOSIS OF CRANIO-MANDIBULAR DYSFUNCTION}

\section{3 - 1 - Differential diagnosis}

This section, which is far from being exhaustive, is intended to bring to the clinician's attention those clinical signs characteristic of a variety of pathoses that have nothing to do with craniomandibular disorder but may trap the unwary practitioner into thinking they do ${ }^{6-29}$. Sinusitis manifests itself primarily as a sensation of heaviness that moves about when patients lower their heads or, when descending a stairway, they get the feeling their noses are clogged up. The principal clinical signs that make diagnosis of this condition more definitive are pain on sub-orbital palpation as well as axial percussion of maxillary teeth whose roots are in proximity to the sinus.

Migraine headaches are characterized by severe pain affecting one side of the brain that last for several days and are accompanied by nausea, vomiting, aversion to light and noise, all obliging the sufferer to seek calm and repose. Migraines must be differentiated from ordinary headaches that are often bi-lateral.
Suddenly occurring buzzing in the ear, exacerbated at night, is called tinnitus. Although it has been widely reported that occlusal adjustments can relieve these symptoms, there is no evidence that such an approach is effective so patients should not be misinformed or mistreated in this regard. The true nature of this disorder remains hotly disputed.

The symptoms of facial neuralgia, which affect the area served by the trigeminal nerve, arrive with brutal rapidity, cause intense pain, and, usually, disappear with equal celerity. Occurring in a "trigger zone," the clinical symptoms of trigeminal neuralgia are painful reflextics. The patient's face undergoes a veritable transformation. Practitioners can treat it only symptomatically by prescribing pain killers. Another form of facial neuralgia, a symptomatic trigeminal type, appears with extremely painful manifestations that appear on an almost fixed schedule and last longer than those of facial neuralgia but do not cause distortion of facial appearance. Patients often assign the blame 


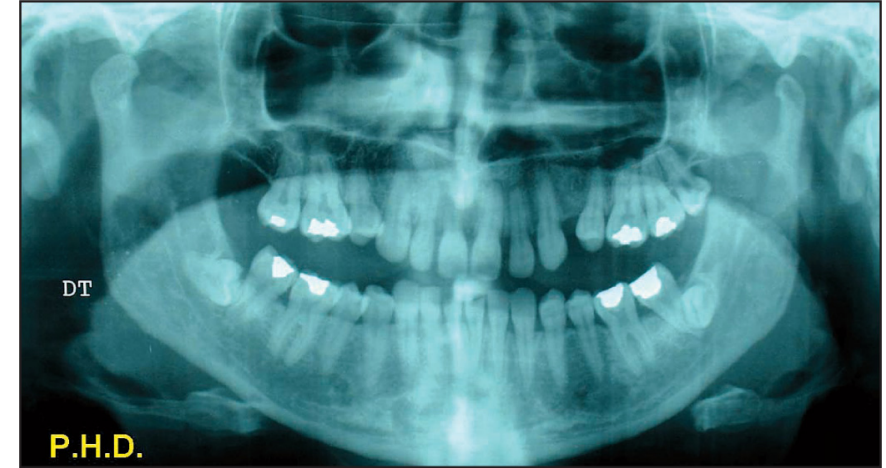

Figure 7

Condylar asymmetry.

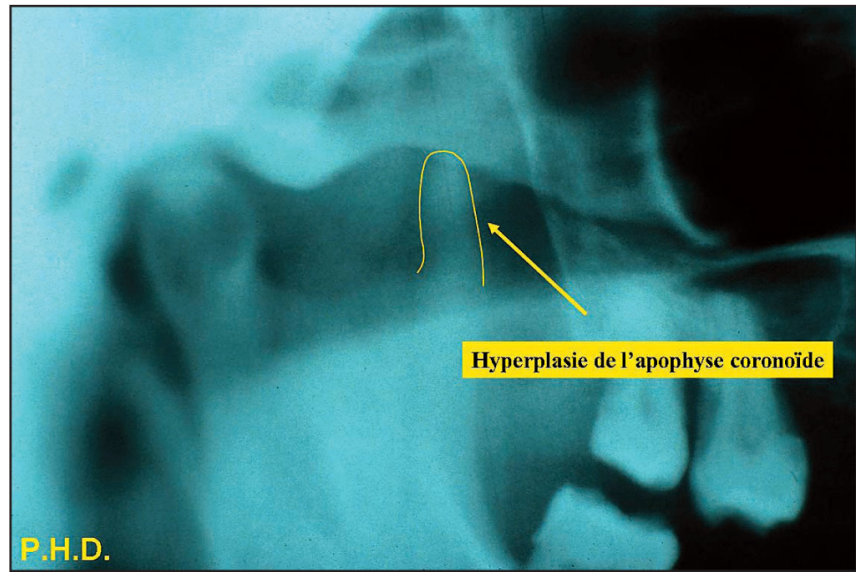

Figure 8

Hyperplasia of the coronoid process. for this condition to a particular tooth they think is involved but that might, in fact, be perfectly healthy.

Poor posture in the work place often leads patients to assume adaptive pain avoidance stances that inevitably have harmful effects on skeletal structures, often cranio-mandibular, with resultant pain that appears in the cervical or lumbar spinal regions.

Hypo or hyperplasia of the condyles, a reflection of abnormal growth or of inflammation dating back to infancy, can be an etiological factor in craniomandibular disorders as can coronoidmalar anomalies and tumerous lesions ${ }^{4,13}$ (fig. 7, 8).

The pain of psychogenic origin that dentists most frequently see in patients is glossodynia, a malady described by patients as painful burning or even biting sensations in the tongue. But the examiner cannot discern any manifest signs.

The permanent pain produced by cranio-mandibular disorders, exacerbated by bruxism, accentuates the anxiety of patients whose complaints are not always taken seriously by the practitioners they visit. But because there is a great risk that patients who suffer consistent pain for six months will become depressed, a great effort should be made to help patients deal with all problems of psychogenic origin such as hypochondria, hysteria. And dentists should deal with the real problems presented by patients in full knowledge of the thin line that separates them from misleading symptoms patients collect, consciously or unconsciously, that might entrap unwary practitioners.

\section{3 - 2 - The intake interview}

Time can be saved in this procedure by having patients fill out detailed questionnaires (fig. 9). Then when the encounter begins, the examining dentist can orient the discussion from the beginning to focus on the essen tial clinical signs. Dentists should employ correct, clear, but not overly complicated terms so that comprehension will be enhanced as much as 
Nom: Prénoms

Age

Profession: Situation de famille:

Nombre d'Enfants

Adresse:...

Par qui êtes vous envoyé ?

Quel est le motif de votre visite?

Avez vous subi des traumatismes ou des chocs violents?

De quel ordre?

Comment?

Quand?.

\section{MARQUER D'UNE (X) LA REPONSE CORRECTE}

Ou avez-vous mal :

- Avez-vous mal à la tête ?

- Avez-vous mal au cou?

- Avez-vous mal aux joues?

Depuis combien de temps?....

En ouvrant la bouche, votre mandibule fait-elle du bruit?

- Sont ce des claquements?

- Sont-ce des crissements ?

- Existent ils à droite ?

- Existent ils à gauche?

Avez vous des difficultés à ouvrir la bouche ? En quelle circonstance?.

Votre mandibule s'est elle déjà bloquée ? En quelle circonstance?.

Souffrez vous de la colonne vertébrale ? A quel niveau?

Avez-vous des vertiges ?

En quelle circonstance?

Avez vous consulté un autre Thérapeute?

Lequel ?.

Avez vous eu des anesthésies générales?

Quand?
La douleur apparaît-elle :

- Le matin?

- L'après-midi ?

- Le soir?

Dans quelles circonstances?

Dans le passé votre mandibule a-t-elle fait du bruit ?

- Du côté droit?

- Du côté gauche?

- Se sont-ils modifiés?

- Se sont ils arrêtés?

Depuis combien de temps?

Avez vous des acouphènes?

Avez vous la sensation d'oreille bouchée?

Serrez vous les dents?

- Le jour?

- La nuit?

Avez vous eu un traitement d'orthodontie ?

Avez vous eu un traitement dentaire récent ?

Souffrez vous d'une maladie générale ?

Laquelle?

Prenez vous des médicaments ?

Lesquels?

Figure 9

Examination form. 
possible. With the questionnaire and the early answers to enquiries, the dentist should soon have a good knowledge of the patient's condition in life, the pains experienced, and whatever oro-facial malfunction or postural and ocular disturbances are present $6,17,28$.

The patients' standing in life is of capital importance because their age, profession, and family situation may reveal the fundamental malady at the heart of the complaint.

That chief complaint may be the patients' concern about the articular sounds they are producing, or pain, or both. Depending upon the seriousness of this symptomology the dentist will advise the patient to have treatment or that no intervention is needed. If the problem is simply nonpainful noise on joint movement with anterior displacement of the disc that cannot be recaptured clinically, occlusal equilibration would be ineffective and should not be undertaken. But if the sounds are accompanied by pain, the dentist should explain to the patient that equilibration could help relieve the pain but that it would not eliminate the noises.

In actual practice patients report trauma to the joint only when the episode has been violent. Serious cranial trauma almost inevitably will cause problems in the tempero-mandibular articulation. Dentists should be alert to the possibility that patients have suffered less dramatic events that did not require hospitalization but may, nevertheless, left behind unperceived dental complications.

Ordinary headaches should be distinguished from migraines, which, it should be remembered, do not respond to pain killing medication and seriously handicap those that are afflicted. For them specific anti-migraine medication may be effective.

Headaches caused exclusively by cranio-mandibular dysfunction are located in the temporal regions. When they occur in the morning they are a residue of nocturnal bruxism. If they appear in the afternoon or the evening they are more likely to be symptomatic of postural or especially ocular problems related to the patient's professional activities ${ }^{11,15,22,25,37}$. Pain is localized in frontal regions primarily over the eyes. Often the patients are secretaries who work all day long in front of a computer. Patients who describe their pains as appearing in their cheeks during prolonged mastication have usually suffered from spasms of the masseter muscles that are the precipitating factor.

Sharp pain that arises during mastication of hard foods is localized in relation to the tempero-mandibular joints. Pain in the cervical region is usually caused by ocular problems related to malfunction of the oculocephalogyric reflexes. In addition to having pain when they turn their heads these patients may also suffer from vertigo.

The length of time the pain has been present is an important factor for the examining dentist to contemplate. A suddenly appearing aggravation of a long standing cranio-mandibular disorder very likely reflects an onset of bruxism stemming from stress in the workplace or from some psychosocial problem. If the pain persists over a period of months the practitioner has to suspect the patient is entering into a period of depression. 
Articular sounds vary in intensity but are always an indication of anterior displacement of the disc. Their tone may change with time, even disappear. By carefully questioning the patient, the practitioner can learn much about the pathology of the tempero-mandibular joint. When the sound diminishes as time goes by this indicates the condition is of long duration. The disappearance of the sound is a sign that an anterior displacement that was once reducible has become intractable. Finally, clicking noise that turns into crepitation should make the practitioner think that the patient is suffering from degenerative arthritis of the tempero-mandibular joints.

Patients may find themselves unable to open their mouths fully upon awakening in the morning, as a result of night time bruxism. When patients declare they heard clicking sounds in the evening and that the limitation appeared suddenly on the following morning, practitioners should suspect that an abrupt irreducible anterior displacement of the disc has occurred. But when the onset of interference in opening is gradual, these clinical signs suggest that increasingly severe muscular spasms are the root cause.

A blockage of mandibular movement that limits mouth opening usually arises when patients are yawning or laughing and is a manifestation of the head of the condyle's passing over the anterior temporal tuberosity. This is a result of the ligaments being so loose that patients are able to reduce the luxation themselves by applying pressure to the mandible. By checking the patient's fingers, the practitioner can determine whether this ligamentary laxity is physiological or pathological. Patients are often unaware that they brux their teeth during their sleep and it is usually a spouse who is kept awake at night by the noise of the grinding of teeth who signal the problem. During the medical interview the bruxing patient will complain of still being tired upon awakening from a night's sleep.

Patients become aware of tinnitus when they hear intense whistling or humming noises at night. It is important for the practitioner to distinguish them from articular sounds. In general patients are well aware of the problem because they have already been told by oto-laryngoligists that there is no medical treatment for this disorder. If patients have consulted a dentist simply because of the noises, they will have to be told dentistry is equally incapable of making the noises go away. But, if the patients also want help fro a cranio-mandibular disorder, the dentist can assure that dental treatment can deal with this problem.

The sensation of a clogged ear is often the sign of an anterior displacement of the disc of long standing. The condyle pushed back into the depths of its temporal fossa by the displaced disc causes the plugged ear sensation because of its close proximity to the auditory canal.

With a good intake interview, the practitioner will have a good idea of what is causing their patients' problems before they have taken the first step in their physical examination. At this stage with the clinical signs neatly presented, the diagnosis is almost completed. The practitioner merely has to fill out the precise details. 


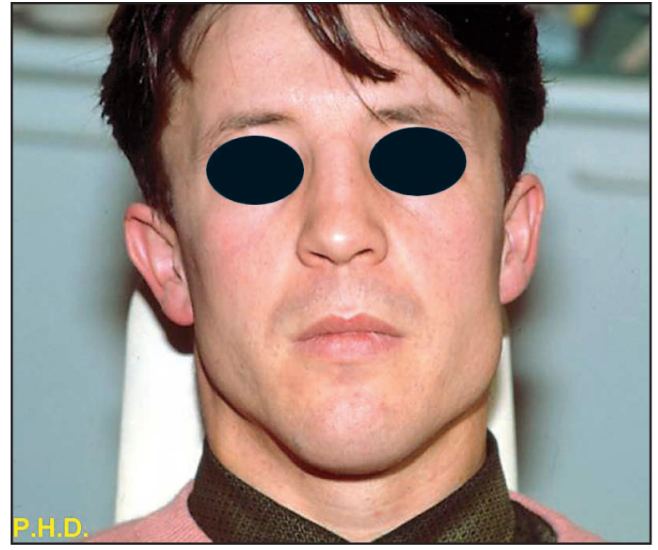

Figure 10

Hypertrophy of the masseter muscle.

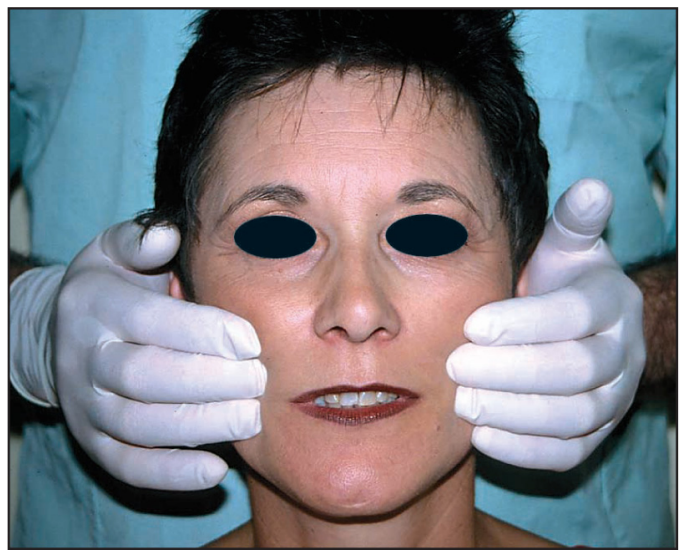

Figure 12

Palpation of the masseter muscles.

\section{3 - 3 - The actual diagnosis}

In order to insure that a non-specialist will be able to make an accurate diagnosis of craniomandibular dysfunction, we shall include here only the essential significant elements needed for it. We shall not describe examinations like mandibular tests, the Farrar diagram or the axiography $^{6,16}$

The diagnosis begins with a simplified occlusal analysis that takes the

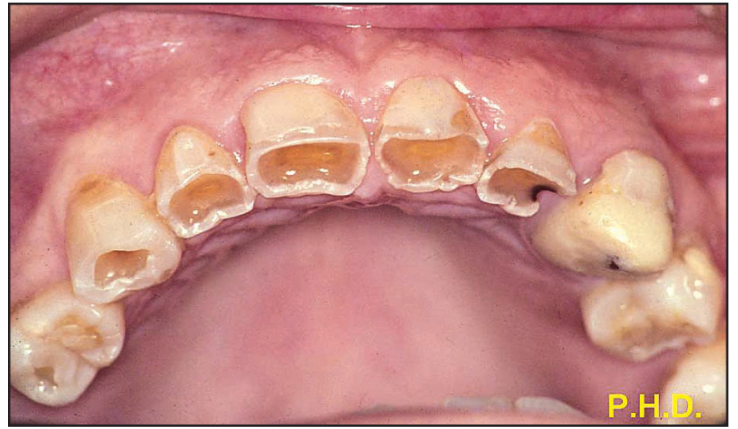

Figure 11

The effect of bruxism on dental enamel.

patient's morphology into account (fig. 10). Dental wear (fig. 11), the relationships between the incisor and canine teeth, the relationship of the upper and lower buccal teeth, the occlusal plane, the teeth that are likely to be lost, the relationship between the incisal frenums, and the vertical dimension are all recorded. The dentist proceeds with the examination by a bi-lateral pal-pation of the muscles of mastication: the masseters (fig. 12); the anterior, middle, and posterior temporals; the median pterygoids; the sterno-cleido-mastoids; and the trapezius. When patients feel pain on palpation of the last two muscle groups the dentist should suspect the presence of a postural problem. The dentist should continue palpation in the region of the tempero-mandibular joint as patients open and close their mouths. When they report pain in closure that indicates a problem with the capsular musculature. Palpation in the retro-articular region can be undertaken when patients open their mouths.

With the stethoscopic auscultation the examining dentist can hear the various articular noises, clicking or grinding noises in the articulation at the beginning, during, and the end of 


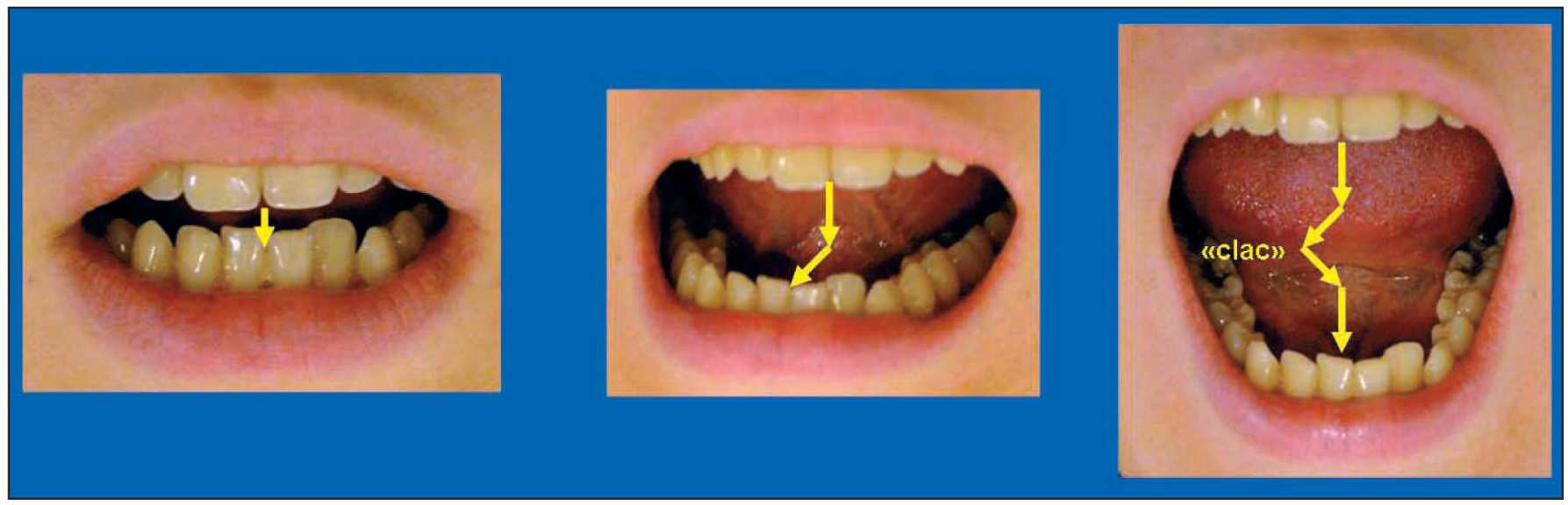

Figure 13

Deviation of the mandible on opening.

mouth opening. Clicking is a sign of anterior displacement of the disc, still more or less reducible, but grinding sounds suggest that the cortical condylar bone has changed in nature or that degenerative arthritis of the tempero-mandibular joint has begun.

The practitioner can assess the mandible in action by observing the midline between the incisors begin to deviate, always in the direction of the affected TMJ, as the mouth opens. If the disc is recaptured it will return to the sagittal plane, accompanied by clicking articular sounds (fig. 13). If this cannot be achieved, the permanent deviation in opening indicates that the displaced disc will never be recaptured. This is verified not only by limited opening with ineluctable devia-

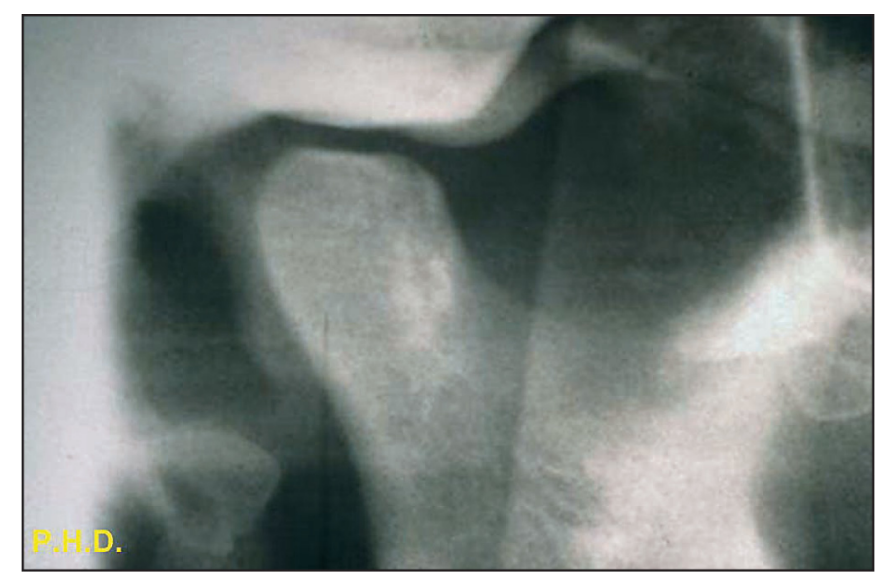

Figure 14

View of degenerative arthritis of the TMJ. 
tion, but also by the feeble lateral movement possible for the articulation to the one affected by the pathology.

The panoramic and trans-cranial radiographs are the primary $\mathrm{X}$-ray tools for detecting eventual deformation of cortical condylar bone ${ }^{30}$ (fig. 14). An examination of the radiographs will indicate whether or not the heads of the condyles are centered in their fossas but it is not correct to assume that this will tell whether or not the discs are displaced in a position anterior to their condyles. Unfortunately, a minor deviation of the cone of the X-Ray machine, imperceptible to the naked eye, can cause major differences in the image produced and seduce practitioners into coming to unjustified conclusions in their diagnoses ${ }^{39,40}$. Practitioners can obtain reliable radiographic pictures of the disc only through Magnetic Resonance Imaging, MRI. This procedure should be employed when there is any confusion about what the diagnosis should be and especially when the insults to the tempero-mandibular joints are of long duration ${ }^{30,35}$. Of course MRI should not be used as a crutch to eliminate the need for a scrupulous and thorough examination and differential diagnosis. The services of the MRI are needed for other, graver medical requirements that, in the grand scale of things, are more serious than anterior displacement of a A condylar disc. Fortunately, axiographic analysis can, to a large extent, serve as a diagnostic substitute tool for the $\mathrm{MRI}^{23,31}$ (fig. 15).

There is no longer any doubt that dental occlusion exerts an influence on posture. Many studies have shown the close relationship between the nerve control of the teeth, posture, and the eyes ${ }^{10,14,18,19,34}$.

Because dentists are not specialists in postures, simple tests have been

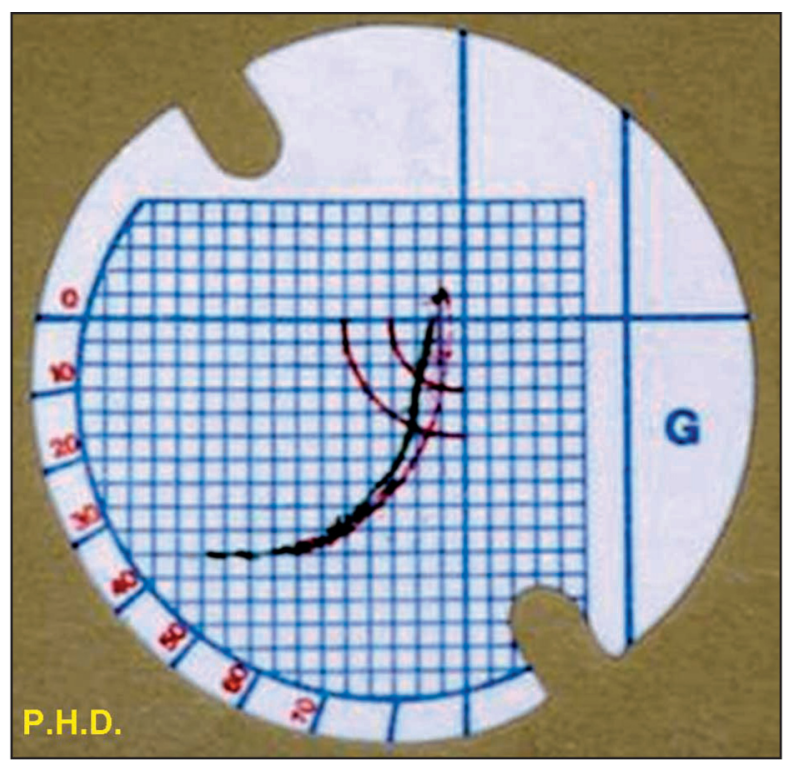

Figure 15

Axiographic tracing of an old incredible disc luxation. 


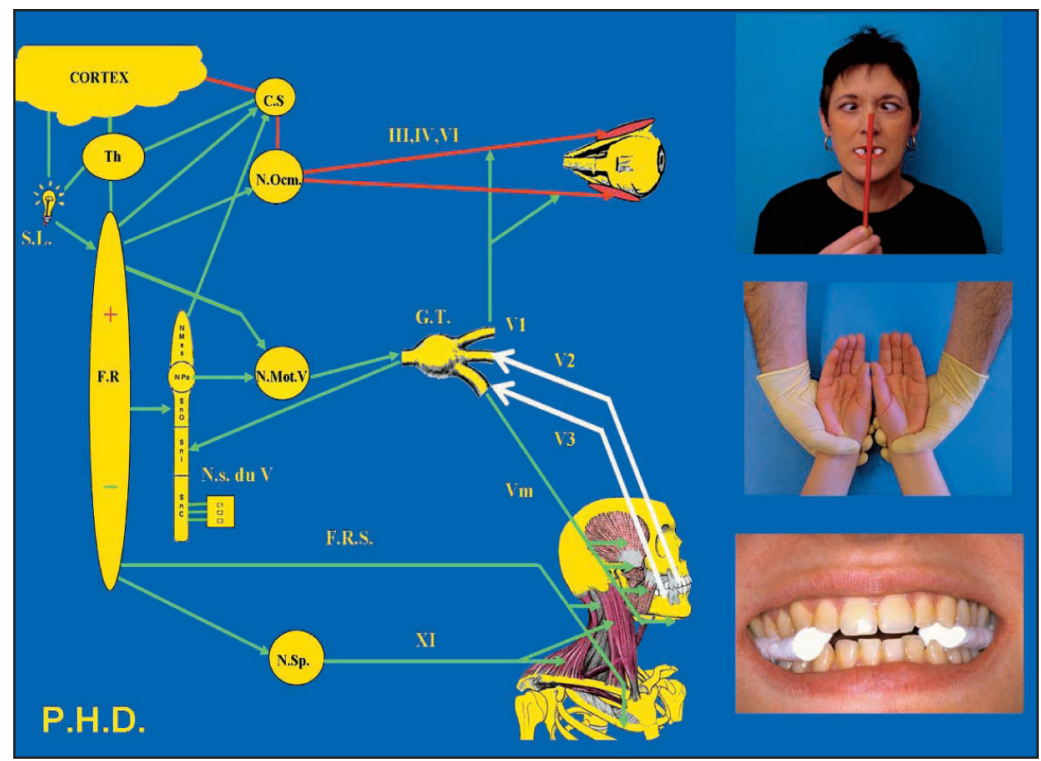

Figure 16

Biting on cotton rolls adjusts posture and restores ocular convergence.

proposed to help them in their diagnostic efforts. The clinical protocol consists of controlling the horizontal posture of the scapular belt and ocular convergence. The dentist assesses the horizontal character of the scapular belt by holding the patient's extended arms at the wrists to control the level of the radial malleoles. To test the patient's oculogyria, or eye movement, the practitioner holds a pencil and brings it up toward the midline asking patients to follow it with their eyes. When examination reveals that the scapular belt is truly horizontal and that patients are able to follow the approaching pencil until lacrimation, or tearing, begins, it can be said that no craniomandibular dysfunction is present. But if the scapular belt tilts and the eyes cease to converge on the approaching pencil some abnormality exists. By asking patients to bite bilaterally on cotton rolls serving as improvised splints, the occlusal disharmony can be remedied clinically ${ }^{7}$ (fig. 16).

In this article that is designed to be useful for all practitioners, we do not propose to go into more detail about postural problems, descending, ascending, or mixed with or without ocular compensation, adapted to posture or primary. Thos who desire to learn more can consult specialized works some of which we have mentioned in the bibliography ${ }^{3,6-8}$.

\section{4 - SIMPLE CLINICAL INFORMATION FOR THE VIGILANT PRACTITIONER}

In order overwhelm the reader with excess information and tempt to extend their diagnostic efforts beyond reasonable limits, we shall now present a few simple clinical signs that will help every practitioner to detect or 
suspect, before treatment, the eventual possibility of craniomandibular dysfunction, all without taking too much time. If this rapidly gathered information leads the practitioner to suspect that cranial pain dysfunction malfunction may crop up during treatment, then they can set about compiling a more exhaustive and precise diagnostic dossier.

\section{4 - 1 - When patients reveal that}

- They have headaches in the morning, they are probably grinding their teeth at night.

- They have headaches during the day, these are probably tension headaches that derive from daily stress, excessive worrying, or sitting in unsatisfactory positions at work, especially at the computer screen.

- They feel pain within their ears when they have difficulty chewing hard foods, they may have temperomandibular joint problems.

- They hear clicking or grinding noises near their ears in opening or closing their mouths there is a strong chance that the disc has been displaced anteriorally from the head of the condyle. Sometimes the clicking is painful, sometimes it is not. This can be accompanied by a feeling of a plugged up ear. Firm closure of the jaws seats the heads of condyles deep in their fossas and the disc blocks them in this position. The proximity of the auditory canal gives patients a sensation of compressed stuffiness in the ears.

- They are having trouble opening their mouths in the morning and have to force the jaws apart before normal conditions return. This is usually ac- companied by a very loud clicking noise that probably means the disc is in advance of the condyle. These patients are very likely grinding their teeth at night when the condyles are forced into the depths of their fossas the disc rolls forward ahead of them. When they awaken the displaced disc blocks the condyle from moving forward and limits mouth opening. In forcing their jaws apart patients help the condyle to pass under and ahead of its disc with a striking clicking sound. At this precise moment the mouth opens normally.

- Their mouth opening is limited. This should make the practitioner think of an irreducible anteriorally displaced disc.

- That their teeth are showing unusually heavy signs of wear, becoming shorter, and more sensitive to hot and cold. If they have no special habits that could be causing this erosion they are undoubtedly performing centric or eccentric nocturnal bruxism, that is grinding or clenching their teeth or both.

\section{4 - 2 - You should ask them if}

- The articular noises change with time and become less audible. If this is the case the disc has worn down because of the long standing nature of the problem.

- If they have heard articular sounds in the past that no longer occur. This indicates that an articular problem that was once reducible is now not reducible.

- If the limitation of mouth opening is recent or progressive. If it is recent, that may mean the blockage has followed the cessation of articular sounds and is a manifestation of an anteriorally displaced disc that cannot 
be recaptured. But if the limitation in opening is progressive with no history of past clicking noises, spasms of the muscles of mastication caused by bruxism may be responsible.

- If they have pain over their eyebrows, around their eyes, or at the base of the orbital cavities. This would probably be caused by spasms of the ocular muscles resulting from imperfectly designed glasses of from difficulty in oculogyria or moving their eyes about.

- If they have pains in the neck, difficulty in focusing on small objects, and dizzy spells. Such symptoms support a diagnosis of ocular problems that are attempts to compensate for eyeglasses made on a prescription for incorrectly refracted eyes, especially if their glasses have progressive lenses.

- If they have pain in the lumbar vertebrae. This would confirm the presence of an ocular disorder but postural problems may also affect the lumbar region. If posture is at fault, the practitioner, or some other specialist, should determine whether the postural problem is ascending, descending, or mixed.

\section{4 - 3 - You observe}

- That mouth opening is limited and skewed to one side. When the mandible always deviates to the side with the pathology, it is essential for the dentist to ask questions about the past history of tempero-mandibular joint.

- A deviated jaw opening that at a certain point re-centers itself. In general this is accompanied by an articular noise. This indicates an anterior discal displacement that can be recaptured. The practitioner should see if this is clinically possible.

- An extremely opening of the jaw on the order of six centimeters. If the finger ligament laxity test is negative, that suggests the looseness of the ligaments in the tempero-mandibular joint is pathological, as a result of a longstanding anterior displacement of the disc that can no longer be recaptured.

- A discrepancy in the placement of the seated patient's feet, indicating one leg is shorter than the other. If the patient is correctly seated in the chair the problem may be a postural one.

The notation of these different indices requires about five to ten minutes of the practitioner's time but this may prove to be time well spent over the course of treatment. If this relatively rapid investigation may spare the dentist from falling into the trap of having a pre-existing, latent condition become blatantly overt while the patient is undergoing treatment that could be falsely accused of being the causative factor. The pretreatment TMJ assessment could save the dentist from allegations of neglect or worse.

of practitioners who do specialize in their treatment to help them exercise vigilance in examining patients before 
embarking upon extensive orthodontic or prosthetic therapy. These practitioners need to know how to detect latent TMJ problems that might express themselves during the course of treatment or after it. Both orthodontists and prosthodontists specialize in providing their patients with a new and healthy arrangement of how the teeth of one jaw interact with the teeth of the other jaw. These new healthy relationships should take place in an environment in which the tempero-mandibular joint and the muscles of mastication that support and work with them are equally healthy.

If the simplified cranio-mandibular assessment leads the practitioner to suspect the patient does, in fact, have an established or a burgeoning craniomandibular disorder, a more precise and intensive examination should be launched that will include palpation of all the muscles of mastication, articular auscultation, mandibular tests, a precise evaluation of mandibular movements as recorded on a Farrar diagram, axiography, a study of radiographic imagery, and postural assessment.
Practitioners should bear in mind that an old pathological event may have produced changes that have often become hidden behind a facade of normality with no apparent clinical signs. This can happen when a disc has been displaced anteriorally without causing any pain or having little or no effect on quasi-normal mandibular movement, remaining undetected unless it is discerned by a vigilant examiner. If nothing is discovered, however, and orthodontic or prosthetic treatment is undertaken in accordance with the standard academic norms, a minor disaster could erupt if the patient is unable to adapt to changes or overcompensates at the wrong moment. This often happens during surgical treatment of the temperomandibular joints. This rather stark intervention will fail when all the essential diagnostic elements have not been taken into consideration ${ }^{21,36}$. In any case, orthopedic treatment, which is far less invasive, is almost universally preferred for therapy of craniomandibular disorders (fig. 17).

In cases of craniomandibular dysfunction, orthodontic treatment alone

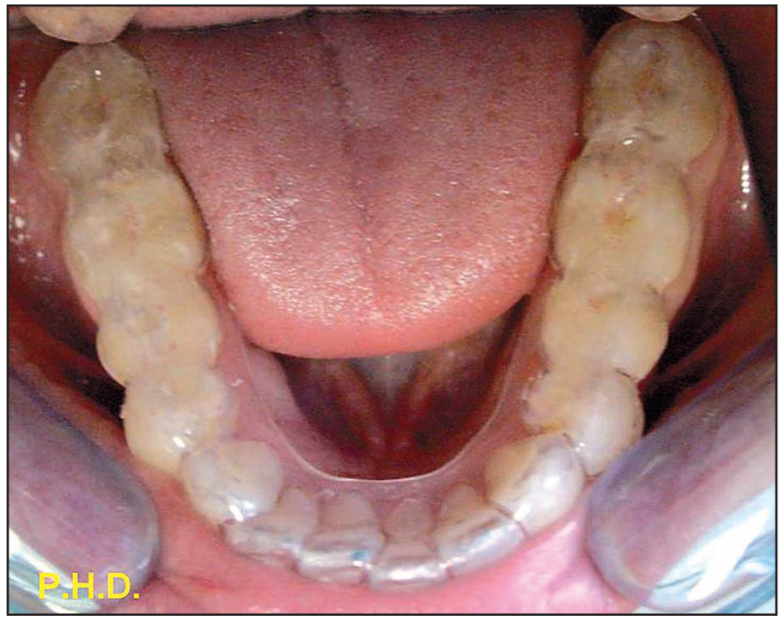

Figure 17

Occlusal splint with total coverage of the mandibular arch. 
cannot substitute for an initial session of orthopedic therapy. It is fallacious thinking to suppose that isolated orthodontic therapy in itself can resolve troubles of the TMJ that have been exacerbated by bruxism. On the other hand, orthodontic therapy can be undertaken in conjunction with the use of a splint to unblock joints that have been immobilized by the steep over-bite of an Angle Class II, Division 2 malocclusion.

By making a precise diagnosis of the type of cranio-mandibular disorder, latent or overt, the patient suffers from, orthodontists will be able to select the most harmonious type of mechano-therapy and avoid being accused, at a later time, of precipitating post-therapeutic articular pain. They will have informed the patient of the possible risks of orthodontic treatment and the benefits that could be derived from an initial orthopedic stage. If the patient refuses it, the orthodontist will be protected against an eventual accusation of being responsible for the patient's eventual post-therapeutic articular compensation.

\section{BIBILIOGRAPHY}

1. Carlson GE, Egermark I, Magnusson T. Predictors of bruxism, other oral parafunctions tooth wear over a 20 year follow-up period. J Orofac Pain 2003;17:50-7.

2. Ciancaglini $R$, Guerlone EF, Radaelli $G$. The relationship of bruxism with craniofacial pain and symptoms from the masticatory system in the adult population. J Oral Rehabil 2001;28:842-48.

3. Clauzade MA, Marty JP. Ortho Posturodontie 2. Perpignan : SEOO Ed, 2006.

4. Derrien G, Predine-Hug F, Jardel V, Robinson JJ. Anomalies coronoïdo-malaires et limitation des mouvements mandibulaires. Cah. Prothèse 2002;118:37-43.

5. Desmons S, Graux F, Atassiu M, Libersa P, Dupas PH. «The Lateral Pterygoid Muscle, a heterogeneous unit implicated in Temporomandibular Disorder: a literature review». Cranio, 2007 Oct;25(4):283-91.

6. Dupas PH. Nouvelle approche du dysfonctionnement cranio-mandibulaire. Du diagnostic à la gouttière. Paris, Editions CdP, 2005.

7. Dupas PH, Dupas G. Occlusodontie et posture. Cah. Prothèse, 2000;110:21-34.

8. Dupas PH, Graux F, Picart B. Mise au point posturale. Stratégie Proth 2003;vol. 3, n 2:155-59.

9. Farrar WB. Characteristics of the condylar path in internal derangements of the TMJ. J Prosth Dent 1978;39:319-32.

10. Flix JD. Neuro anatomie. Traduction de Antoine Dhem Bruxelles, De Boeck et Larcier, édit., 1996.

11. Gavish A, Halachmi M, Winocur E, Gazit E. Oral habits and their association with signs and symptoms of temporomandibular disorders in adolescent girls. J Oral Rehab. 2000,27:22-32.

12. Guyton AC. Basic Neuroscience. Anatomy and Physiology. Padoue, Piccin Nuova Libraria, 1996.

13. Hernandez-Alfaro F, Escuder O, Marco V. Joint formation between an osteochondroma of the coronoid process and the zygomatic arch (Jacob disease): report of case and review of literature. J Oral Maxillofac Surg 2000;58(2):227-32.

14. Kahle W, Leonhardt $H$, Platzer W. Anatomie. Système nerveux. Paris, Flammarion, édit., 1993. 
15. Kato T, Thie N, Montplaisir J, Lavigne GJ. Bruxism and orofacial movements during sleep. Dent Clin North Am 2001;79:657-84.

16. Laplanche O, Pedeutour P, Duminil G. Mahler P. Dépistage des anomalies de I'occlusion. Réalités cliniques 2004;15(2):141-56.

17. Lavigne G, Goulet JP. Questionnement sur le rôle des activités oro-faciales dans la douleur temporo-mandibulaire. Réalités cliniques 2004;15(2):119-32.

18. Leblanc A. Les nerfs crâniens. Paris, Springer-Verlag, édit., 1995.

19. Lee WY, Okeson JP, Lindroth J. The relationship between forward head posture and temporomandibular disorders. J Orofac Pain 1995;9:161-5.

20. Mello et al, "Update on stress and depression: the role of the hypothalamic-pituitaryadrenal (HPA) axis", Rev Bras Psiquiatr, 2003;25:231-8.

21. Mercury LG. Eminectomy and discoplasty for correction of the displaced temporomandibular joint disc Discussion. J Oral Maxillo-Fac Surg 1989;47:153-4.

22. Molina OF, Dos Santos J, Mazzetto M, Nelson S, Nowlin T, Mainieri ET. Oral jaw behaviors in TMD and bruxism : a comparison study by severity of bruxism. J Craniomandib Pract 2001;19:114-22.

23. Parlett K, Paesani D, Tallents $\mathrm{RH}$, Hatala MA. Temporomandibular joint axiography and MRI findings: a comparative study. J Prosthet Dent 1993;70(6):521-31.

24. Philips et al, "Stress, the hippocampus and the hypothalamic-pituitary-adrenal axis: implications for the development of psychotic disorders" Australian and New Zealand Journal of Psychiatry 2006;40:725- 41.

25. Riley III JL, Benson MB, Gremillion HA, Myers CD, Robinson ME, Smith CL, Waxenberg LB. Sleep disturbances in orofacial pain patients: pain related or emotional distress? J Craniomand Pract 2001;19:106-13.

26. Riley III JL, Gilbert GH. Orofacial pain symptoms: an interaction between age and sex. Pain 2001;90:245-56.

27. Rozencweig D. Le bruxisme est-il un symptöme névrotique. Rev Med Parodont 1974;2:45-50

28. Rozencweig D. Syndrome algo-dysfonctionnel de l'appareil manducateur: une fiche d'observation simplifiée. Cah Prothese 1979;26:113-9.

29. Rozencweig D. Algies et Dyfonctionnements de I'Appareil Manducateur. Paris : Editions CdP, 1994

30. Rozencweig D, Gerdolle D, Delgoffe C. Imagerie de I'ATM. Aide au diagnostic des troubles cranio-mandibulaires. Paris : Editions CdP, 1995.

31. Rozencweig G. Evaluation comparative de deux moyens d'investigation des dysfonctions cranio-mandibulaires : I'axiographie et I'IRM. Rev Orthop Dent Fac 1991;25:20513.

32. Rozencweig G. Laxité ligamentaire et dysfonctions intracapsulaires de I'ATM. Inform Dent 1991;26:2157-63.

33. Schindler HJ, et al., Differential activity patterns in the masseter muscle under simulated clenching and grinding forces. J Oral Rehabil 2005;32(8):552-63.

34. Sobatta J. Atlas d'Anatomie Humaine. Tome 1. Paris. Editions Médicales Internationales, 1995.

35. Spitzer WJ. Magnetic resonance imaging of the temporo-mandibular joint meniscus. Rev Stomatol Chir Maxillofac 1990;91:123-5. [17] Watt DM. Gnathosonic diagnosis and occlusal dynamics. New York: Praeger Ed, 1981.

36. Takaku S, Toyoda T. Longterm evaluation of discectomy of the temporomandibular joint. J Oral Maxillo-Fac Surg 1994;52:722-26.

37. Torabi-Teherani M, Gabriele M, Joerger R, Hedelin G, Petiau C, Krieger J, Leize M. Occlusion, muscles et ATM pendant le sommeil: Etude polysomnographique et clinique. Cah Prothese 2000;112:7- 23.

38. Watt DM. Gnathosonic diagnosis and occlusal dynamics. New York: Praeger éd, 1981.

39. Weinberg LA. Correlation of temporomandibular dysfunction with radiographic findings. J Prosth Dent 1972;28:519-39. 
40. Weinberg LA. Pratical evaluation of the lateral temporomandibular joint radiograph. J Prosth Dent 1984;51:676-85.

41. Weinberg S, Lapointe H. Cervical extension-flexion injury (whiplash) and internal derangement of the temporomandibular joint. J Oral Maxillo-Fac Surg 1987;45:653-6. 